\title{
SOSIALISASI BUDAYA SUNDA KEPADA MAHASISWA ASING MELALUI PENGENALAN KULINER SUNDA
}

\author{
Muhamad Adji, Taufik Ampera, Tatang Suparman \\ Fakultas Ilmu Budaya Universitas Padjadjaran \\ E-mail: m.adji@unpad.ac.id
}

\begin{abstract}
ABSTRAK. Kegiatan sosialisasi kuliner Sunda bertujuan untuk memperkenalkan budaya Sunda kepada mahasiswa asing yang tinggal di wilayah Jawa Barat karena semakin banyak mahasiswa asing yang ingin mengetahui budaya Sunda. Pengenalan kuliner Sunda merupakan pintu masuk bagi mahasiswa asing untuk mengenal dan memahami budaya Sunda lebih dalam. Diharapkan dari kegiatan ini, mahasiswa asing akan semakin mengenal budaya Sunda dan dapat memperkenalkannya ke pentas internasional melalui mobilitas global mereka. Hal itu akan membuat budaya Sunda semakin bergaung di dunia internasional. Metode yang digunakan dalam kegiatan ini adalah metode ceramah, metode interaktif dengan alat peraga (produk makanan dan poster), penyebaran kuesioner, dan wawancara. penyuluhan dengan alat bantu produk makanan dan alat peraga (poster). Penggunaan alat peraga bertujuan untuk memudahkan mahasiswa asing mengenal dan mengetahui kuliner Sunda meskipun dengan kemampuan berbahasa Indonesia mereka yang masih terbatas. Hasil kegiatan menunjukkan bahwa kegiatan sosialisasi kuliner Sunda dengan alat peraga berupa makanan Sunda dan poster makanan berfungsi sangat efektif dalam meningkatkan pengetahuan dan pemahaman mahasiswa asing terhadap kuliner Sunda.
\end{abstract}

Kata kunci: Sosialisasi; Budaya; Kuliner Sunda; BIPA; mahasiswa asing

\begin{abstract}
Sundanese culinary socialization activities aim to introduce Sundanese culture to foreign students living in West Java because more and more foreign students want to know Sundanese culture. The introduction of Sundanese culinary is the entrance for foreign students to get to know and understand Sundanese culture more deeply. It is expected that from this activity, foreign students will become familiar with Sundanese cuisine and can introduce it to the international stage through their global mobility. That will make Sundanese culture more resonant in the international world. The method used in this activity is the lecture method, interactive methods with teaching aids (food products and posters), questionnaires, and interviews. The use of teaching aids aims to make it easier for foreign students to know Sundanese cuisine even though their Indonesian language skills are still limited. The results of the activity showed that Sundanese culinary socialization activities with teaching aids in the form of Sundanese food and food posters functioned very effectively in increasing foreign students 'knowledge and understanding of Sundanese cuisine.
\end{abstract}

Keywords: socialization; Culture; Sundanese cuisine; BIPA; foreign student

\section{PENDAHULUAN}

Jawa Barat merupakan salah satu tujuan favorit bagi mahasiswa asing untuk belajar di Indonesia. Hal ini disebabkan karena Jawa Barat kaya akan sumber daya alam dan budaya. Selain itu, di Jawa Barat juga terdapat perguruan-perguruan tinggi yang terkemuka di Indonesia dengan prestasi mendunia. Tiga perguruan tinggi di Jawa Barat yaitu Universitas Padjadjaran, ITB, IPB, termasuk ke dalam 10 kampus terbaik di Indonesia versi QS World University Rankings 2019 (Kumparan, 2018). Kedua alasan ini membuat Jawa Barat menjadi salah satu tujuan favorit bagi mahasiswa asing untuk tinggal dan melanjutkan studi. Salah satu dampaknya adalah bahwa kampus-kampus di Jawa Barat telah menjadi mitra pemerintah Indonesia yang dipercaya secara kontinyu untuk menjalankan program kerja sama pemerintah Indonesia dengan negara-negara mitra sebagai kampus bagi mahasiswa asing untuk belajar.

Pemerintah Indonesia meyakini bahwa mahasiswa asing yang tinggal di Indonesia memiliki potensi untuk menjadi sumber daya manusia yang dapat menciptakan hubungan baik antara Indonesia dan negara Indonesia. Hal ini disebabkan karena mereka dapat menjadi ujung tombak yang dapat memperkenalkan Indonesia ke pentas internasional, minimal ke negara mereka sendiri. Posisi mereka sebagai warga dunia dan keberadaan media sosial yang berkembang pesat belakangan ini juga memudahkan bagi mahasiswa asing tersebut untuk memperkenalkan budaya Indonesia yang mereka kenal. Hal ini menjadi strategi diplomasi budaya yang sangat efektif bagi Indonesia.

Diplomasi budaya adalah diplomasi yang dijalankan dengan menggunakan perangkat sosial dan budaya. Diplomasi budaya bertujuan untuk memberikan pemahaman atas negara, sikap, institusi, kepentingan nasional, dan kebijakan-kebijakan negara dengan melalui pemahaman berbagai hasil budaya (Tuch, 1990: 3. Gouveia, 2006: 7-8, dikutip J. Wang, 2006 dalam Henida, 2008). Diplomasi budaya menawarkan sesuatu yang tidak dapat ditawarkan oleh diplomasi politik, ekonomi, dan terutama diplomasi militer (Ha, 2016). Dengan kekhasannya tersebut, diplomasi budaya dianggap tepat untuk menampilkan wajah Indonesia yang ramah dan bersahabat dalam kancah pergaulan dunia. Hal ini secara tidak langsung akan menarik warga negara asing untuk datang ke Indonesia sehingga secara tidak langsung hal itu akan meningkatkan sektor pariwisata dan ekonomi.

Hal tersebut tentu harus diimbangi dengan pemahaman yang baik dari mahasiswa asing terhadap budaya Indonesia. Masalahnya adalah tidak semua mahasiswa asing yang datang ke Indonesia secara otomatis akan 
mempelajari budaya Indonesia. Biasanya orang asing mengenal budaya Indonesia secara otodidak karena perguruan tinggi-perguruan tinggi tempat mahasiswa asing tersebut belajar hanya menyediakan kurikulum dan fasilitas pembelajaran sesuai dengan bidang keilmuan yang akan ditekuni oleh mahasiswa asing. Sebagai contoh, program pengajaran BIPA(Bahasa Indonesia bagi Penutur Asing) tempat mahasiswa asing belajar bahasa Indonesia di Universitas Padjadjaran, lebih menitikberatkan pada pengajaran bahasa Indonesia dan hanya sedikit menyentuh aspek budaya Indonesia. Sementara itu, interaksi mereka dengan masyarakat lokal juga tidak dapat dikatakan berlangsung intens karena kemampuan berbahasa Indonesia mereka yang masih minim. Akibatnya, dalam kehidupan sehari-sehari mahasiswa asing sering mengalami kesulitan beradaptasi dengan lingkungan sosial budaya tempat mereka tinggal yang berujung pada kondisi gegar budaya (shock culture). Jika tidak diantispasi, hal ini dapat menyebabkan munculnya persepsi negatif dari mahasiswa terhadap Indonesia. Oleh karena itu, mahasiswa asing perlu diperkenalkan dengan aspek budaya lokal. Karena mereka tinggal di Jawa Barat, budaya yang perlu mereka pelajari adalah budaya Sunda.

Budaya, menurut A.B. Taylor, adalah keseluruhan yang kompleks yang di dalamnya terkandung ilmu pengetahuan, kepercayaan, kesenian, moral, hukum, adatistiadat, dan kemampuan yang lain serta kebiasaan yang

Gambardidpastemporusia sebagai anggota masyarakat (Harsojo, 1988: 92). Dengan demikian, aspek budaya sangat luas, tidak hanya berkaitan dengan kesenian saja. Untuk menyederhanakan kopleksitas budaya, C. Kluckhohn dengan mengklasifikasi kebudayaan ke dalam tujuh unsur kebudayaan yaitu 1) sistem ekonomi/ mata pencarian, 2) sistem teknologi/ peralatan hidup, 3) religi, 4) kesenian, 5) organisasi sosial, 6) bahasa, dan 7) sistem kekuasaan. Budaya tersebut terdiri atas wujud terlihat (tangible) dan wujud yang tidak terlihat (intangible). Dinyatakan oleh J.J. Honigmann (dalam Koentjaraningrat, 2005: 74) budaya tangible adalah activities/ kegiatan dan artifact (artefak), sedangkan budaya intangible adalah idea/ gagasan. Sementara itu, budaya Sunda, menurut Dienaputra, adalah budaya yang berlaku pada suku bangsa Sunda. Berdasarkan wilayah geografis, suku bangsa Sunda ini adalah orang-orang yang menempati bekas wilayah Kerajaan Pajajaran yang kemudian berdiri sendiri, yakni Sumedang Larang, Banten, Cirebon, dan Galuh. (2011: 105). Seperti dinyatakan Zakaria dkk. (2011), aspek-aspek budaya Sunda juga memiliki tujuh unsur budaya seperti yang dikemukakan Kluckhohn di atas.

Budaya yang perlu dipelajari oleh mahasiswa asing setidaknya adalah budaya yang dekat dengan kehidupan mereka, salah satunya adalah kuliner. Kuliner diyakini merupakan aktivitas diplomasi budaya yang memiliki peran signifikan saat ini. Hal ini seiring dengan makin kompleksnya isu-isu dalam hubungan internasional sehingga aktivitas diplomasi dituntut berperan lebih signifikan dan efektif untuk kepentingan nasional (Pujayanti, 2017). Oleh karena itu, muncul alternatif diplomasi dalam bentuk gastrodiplomasi (gastrodiplomacy) yaitu diplomasi budaya yang menggunakan makanan sebagai sarana untuk meningkatkan brand awareness bangsa. Rockower menyatakan bahwa gastrodiplomasi merupakan "the best way to win hearts and mind is through the stomach" (cara terbaik untuk memenangkan hati dan pikiran adalah melalui perut). Pernyataan ini menunjukkan bahwa kuliner merupakan aspek budaya yang paling strategis dalam menciptakan pemahaman budaya yang positif pada orang asing terhadap Indonesia.

Dengan mengenal dan memahami kuliner Sunda, mahasiswa asing akan semakin mencintai budaya Sunda sehingga ketika mereka pulang kembali ke negara asal mereka, mereka dapat mengenalkan budaya Sunda di negara mereka, bahkan di negara-negara lain melalui perangkat teknologi global. Dengan demikian, budaya Sunda akan semakin dikenal di dunia internasional. Hal ini akan memberi pengaruh positif pada Provinsi Jawa Barat, khususnya, dan Indonesia secara umum sehingga akan memberi efek positif terhadap bidang ekonomi, investasi, pariwisata, dan budaya.

Dengan adanya sosialisasibudaya Sunda, mahasiswa asing yang sedang menuntut ilmu di Provinsi Jawa Barat tidak hanya mengenal dan mengetahui budaya Sunda, tetapi mereka juga akan dapat memahami karakteristik budaya Sunda, bahkan tidak tertutup kemungkinan di waktu yang akan datang mereka terlibat dalam kegiatankegiatan budaya Sunda di Jawa Barat. Langkah ini akan semakin menguatkan citra Jawa barat sebagai wilayah yang kental dengan nilai-nilai budaya lokal Kesundaan, sekaligus juga sebagai provinsi yang memiliki wawasan global karena telah mengikutsertakan mahasiswa asing dalam setiap kegiatan kebudayaan.

Berdasarkan latar belakang di atas, maka rumusan masalah yang dijadikan fokus kegiatan pengabdian ini adalah:

1. Bagaimana kuliner Sunda disosialisasikan kepada mahasiswa asing melalui pembelajaran budaya pada Program BIPA?

2. Bagaimana respons mahasiswa asing terhadap kuliner Sunda setelah dilaksanakan Program Sosialisasi?

\section{METODE}

Dalam kegiatan pengabdian ini, metode yang digunakan adalah metode ceramah dan berifat interaktif. Yang lebih ditekankan dalam kegiatan ini adalah interaksi dua arah yang terjalin secara intensif antara mahasiswa asing dengan narasumber yang dibantu oleh mahasiswa Unpad program KKNM Terintegrasi. Kegiatan pengabdian ini juga menghadirkan berbagai macam ragam kuliner Sunda untuk dilihat dan dirasakan secara langsung oleh mahasiswa asing. Agar semakin mudah dipahami, penjelasan kuliner Sunda dibantu dengan media poster. 
Sasaran kegiatan pengabdian adalah mahasiswa asing yang sedang belajar Bahasa Indonesia di Pusat Bahasa, Fakultas Ilmu Budaya, Universitas Padjadjaran. Para mahasiswa BIPA tersebut merupakan mahasiswa peserta program reguler, pertukaran mahasiswa, penerima beasiswa Kemitraan Negara-negara Berkembang (KNB) dan penerima beasiswa Darmasiswa. Mereka berasal dari berbagai negara di antaranya Jepang, Korea Selatan, Thailand, Laos, Vietnam, Madagaskar, Tajikistan, Nigeria, dan Kenya. Para mahasiswa asing inilah yang akan menjadi subjek sosialisasi untuk memperkenalkan budaya sunda.

Kegiatan pengabdian ini berlokasi di Pusat Bahasa Fakultas Ilmu Budaya, Universitas Padjadjaran, Jalan Dipati Ukur, Kelurahan Lebak Gede, Kecamatan Coblong, Bandung. Lokasi tersebut dipilih karena lembaga tersebut merupakan tempat mahasiswa asing belajar Bahasa Indonesia untuk Penutur Asing (BIPA).

Dalam pengambilan data digunakan metode wawancara dan kuesioner. Metode kuesioner digunakan untuk memperoleh jawaban atas pertanyaan-pertanyaan seputar pengetahuan dan respons mereka terhadap kegiatan. Metode wawancara digunakan untuk memperoleh jawaban yang lebih dalam dan lebih spesifik dari responden yang tidak terwadahi oleh pertanyaan dana jawaban dalam kuesioner.

\section{HASIL DAN PEMBAHASAN}

\section{Proses Kegiatan Sosialisasi Kuliner Sunda}

Sosialiasi kuliner Sunda merupakan kegiatan yang memperkenalkan berbagai makanan Sunda. Kegiatan ini tidak hanya menunjukkan berbagai jenis makanan Sunda, tetapi juga menjelaskan bahan-bahan makanan tersebut, cara membuatnya, serta aspek sejarah dan budayanya, misalnya kapan biasanya orang Sunda mengonsumsi makanan tersebut. Karena kemampuan berbahasa Indonesia mahasiswa asing ini masih terbatas, sosialisasi kuliner Sunda dibantu menggunakan beberapa alat peraga yaitu poster dan makanan dalam bentuk fisik. Poster-poster ini dipajang di ruangan kegiatan untuk membantu mahasiswa asing lebih mudah memahami kuliner Sunda tersebut. Posterposter tersebut berisi penjelasan sederhana tentang jenis makanan, bahan-bahannya, dan cara membuatnya. Contohnya seperti pada gambar 1 dan 2 di bawah ini. Gambar 1 dan 2 menunjukkan makanan khas Sunda yaitu lotek dan sayur asem. Di dalam poster tersebut ditampilkan bahan-bahan makanan dan bumbu yang diperlukan serta cara membuatnya.

Setelah penjelasan umum tentang berbagai macam makanan, bahan-bahan, dan cara membuatnya, yang dibantu dengan alat peraga berupa poster-poster yang ditempel di dinding tempat kegiatan, mahasiswa asing diajak untuk melihat satu per satu makanan Sunda yang ditampilkan dalam kegiatan tersebut. Pada kesempatan ini, mahasiswa asing dapat mencicipi makanan tersebut

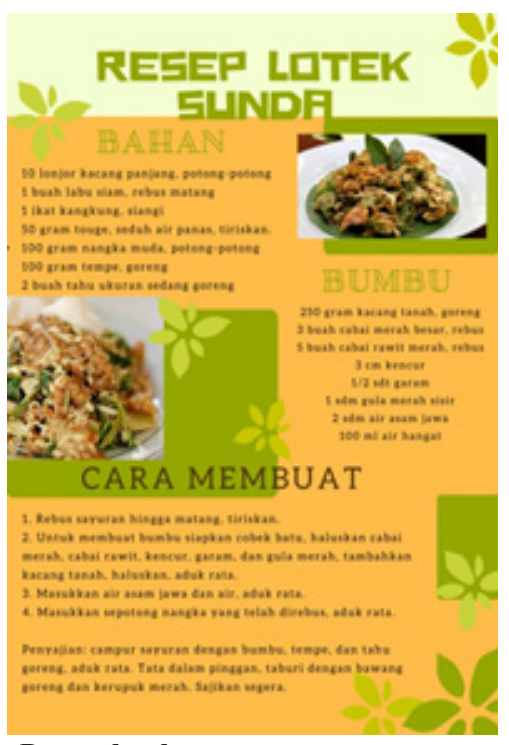

Gambar 1. Poster lotek

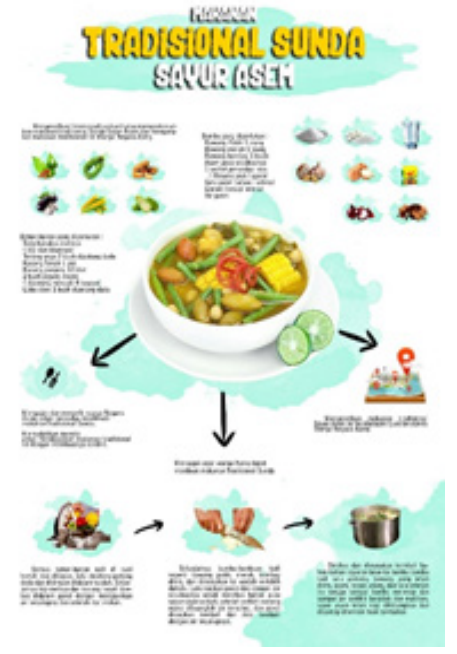

\section{Gambar 3 Poster sayur asem}

dan dapat melakukan tanya jawab dan diskusi dengan tim kegiatan pengabdian. Dengan melihat langsung dan mencicipi makanan tersebut, mahasiswa asing dapat melihat bentuk, warna, dan merasakan tekstur dan rasa makanan Sunda tersebut. Hal ini akan berpengaruh pada pemahaman mahasiswa asing yang lebih baik terhadap makanan Sunda jika dibandingkan dengan hanya berupa penjelasan saja.

Hal tersebut tampak pada gambar di bawah ini. Gambar 3 menunjukkan beberapa jenis makanan Sunda yaitu tahu sumedang, kue cubit, dan kue papais atau yang lebih dikenal dengan nama kue bugis. Dari penampakan ketiga jenis makanan tersebut, mahasiswa asing dapat melihat dan bentuk, warna, dan teksturnya yang berbeda. Begitu pula ketika mereka mencicipinya, dapat dirasakan bagaimana macam-macam rasa pada ketiga makanan tersebut. Dalam kesempatan ini, mereka akan mencoba mengidentifikasi makanan tersebut dengan kosa kata yang mereka miliki. Jika mereka tidak memiliki perbendaharaan kata untuk mewakili apa yang mereka lihat dan rasakan, mereka dapat berdiskusi dengan tim pengabdian, seperti yang tampak pada gambar 4. Mereka dapat mengeksplorasi 
berbagai hal yang mereka lihat dengan berbagai pertanyaan yang mereka sampaikan pada tim pengabdian. Mereka juga dapat membandingkan makanan Sunda dengan makanan dari negara mereka, baik dari persamaan maupun perbedaannya.

Acara berlangsung menarik karena mahasiswa asing sangat antusias mengetahui berbagai jenis kuliner Sunda. Kolaborasi antara mahasiswa asing dan orang Indonesia yang sama-sama berstatus sebagai mahasiswa dalam kegiatan sosialisasi kuliner tersebut menghasilkan pengalaman budaya yang menarik. Mereka sama-sama belajar. Mahasiswa asing belajar tentang kuliner Sunda dari mahasiswa Indonesia dan berkomunikasi langsung dengan penutur jati bahasa Indonesia, sedangkan mahasiswa Indonesia belajar tentang kerakteristik mahasiswa asing dari berbagai negara dengan ciri khasnya masing-masing. Hal ini secara tidak lansung juga memberi pengalaman berarti bagi mahasiswa Indonesia sebagai persiapan untuk menjadi bagian dari masyarakat dunia.

\section{Respons Mahasiswa Asing terhadap Kuliner Sunda}

Kegiatan pengabdian ini diharapkan memperoleh luaran yang positif dalam rangka memperkenalkan budaya Sunda kepada mahasiswa asing. Untuk mengetahui respons mahasiswa asing terhadap kuliner Sunda, kami membagikan kuesioner kepada mereka untuk diisi. Tanggapan mereka pada umumnya sangat positif. Hal itu terlihat dari hasil analisis atas kuesioner yang diisi oleh para mahasiswa asing seperti yang tersaji pada tabel diagram di bawah ini.

Sebanyak 12 kuesioner dapat dihimpun dari mahasiswa asing tersebut. Berdasarkan jawaban kuesioner, seperti yang tampak pada Bagan 1, didapatkan hasil bahwa makanan yang paling tidak disukai mahasiswa asing di antara beberapa makanan tradisional Sunda yang disajikan adalah sayur asem dan cilok. Hal ini ditunjukkan oleh persentase sebesar 25\% untuk sayur asem, 25\% cilok, $17 \%$ lotek, $17 \%$ tahu sumedang, $8 \%$ kue bugis, dan $8 \%$ bala-bala. Dari Bagan 1 di atas dapat disimpulkan bahwa makanan yang paling tidak disukai itu adalah sayur asem dan cilok, sedangkan beberapa makanan yang lainnya yang tidak terlalu disukai adalah tahu sumedang, lotek, bala-bala, dan kue bugis. Alasannya, kebanyakan mahasiswa asing yang memilih sayur asem karena tidak suka dengan sayuran.

Makanan yang paling disukai mahasiswa asing, seperti yang tampak pada Bagan 2, ditempati oleh awug dengan persentase sebesar 33\%. Sementara itu, makanan yang memiliki persentase kedua terbesar berikutnya adalah siomay dengan persentase sebesar 25\%. Selanjutnya, yang menempati persentase terbesar ketiga adalah balabala dan kue cubit sebesar $17 \%$. Pada urutan persentase terendah sebesar $8 \%$ ditempati oleh makanan tradisional tahu sumedang. Awug menjadi makanan paling favorit karena sebanyak 4 responden mahasiswa asing memilih awug dengan alasan karena mahasiswa asing suka dengan makanan yang manis, dan mirip dengan makanan di negaranya. Keunikannya, tidak ada makanan yang menjadi mayoritas atau mendominasi dalam hal yang paling difavoritkan.

Pada kedua Bagan Lingkaran di atas ditunjukkan hasil yang menentukan dan memperhitungkan hasil antara makanan yang paling tidak disukai dan disukai. Makanan yang paling tidak disukai di atas itu ada dua yaitu sayur asem dan cilok dengan memilki persentase yang sama sebesar $25 \%$, sedangkan makanan yang paling disukai berdasarkan grafik yang kedua adalah makanan tradisional awug dengan persentase sebesar 33\%. Tentu saja mahasiswa asing memilih makanan yang paling mereka sukai dan tidak mereka sukai berdasarkan standar mereka masing-masing dan berdasarkan selera yang ada di negara mereka.

Berdasarkan hasil wawancara mendalam, mahasiswa asing menentukan suka atau tidak suka terhadap makanan Sunda didasarkan pada kebiasaan makanan yang mereka buat, bahan makanan yang tersedia, karena masalah kesehatan, mengenai tampilan makanan, dan sebagainya. Hal-hal tersebut menentukan tingkat atau hasil penilaian mereka terhadap makanan yang paling mereka sukai dan tidak sukai.

Dalam kuesioner, kami juga mengajukan pertanyaan yang berkaitan dengan tindak lanjut dari tanggapan mereka terhadap kuliner Sunda. Semua mahasiswa asing menjawab ingin mencoba membuat salah satu makanan Sunda yang disajikan meskipun beberapa jawaban mahasiswa asing tidak secara spesifik. Secara umum, mahasiswa asing beranggapan bahwa makanan yang paling mudah dibuat adalah bala-bala, seperti tampak pada Bagan 3 di bawah ini.

Pada Bagan 3 di atas, sebanyak 8 dari 12 responden menilai bahwa bala-bala adalah makanan yang paling mudah dibuat. Mereka memilih bala-bala karena sering melihat cara pembuatan bala-bala yang dilakukan pedagang yang berjualan di sekitar kampus atau tempat tinggalnya di Bandung. Selain itu, ada beberapa faktor lain yang menjadi penentu penilaian mereka terhadap makanan yang terlihat mudah untuk dibuat, yaitu tampilan dari makanan itu sendiri, bentuk, bahan-bahan dan berdasarkan selera makanan yang mereka sukai. Sementara itu, sisanya menilai siomay dan cilok adalah makanan yang paling mudah dibuat. Meskipun demikian, tidak semua dari mereka merasa ingin mencoba membuat makanan yang menurut mereka paling mudah dibuat tersebut. Mereka lebih tertarik untuk membuat makanan yang lainnya yang dirasa lebih menarik.

Sebanyak 4 dari 12 responden menyebutkan bahwa mereka ingin mencoba membuat awug dan mungkin akan mencoba membuatnya ketika mereka sudah pulang ke kampung halaman mereka. Yang lainnya bahkan ada yang menyebutkan bahwa mereka mungkin akan mencoba membuat nasi tumpeng, kue bugis, lotek, dan tahu sumedang. Dibandingkan dengan bala-bala, makanan- 
makanan ini lebih sulit untuk dibuat dan memiliki rasa yang lebih kaya, kecuali tahu sumedang. Ketika diwawancara, salah satu responden dari daratan Afrika menyebutkan bahwa dia ingin mencoba membuat awug karena rasanya enak dan teknik membuat makanannya mirip dengan makanan di negara asalnya, hanya saja tidak ada makanan yang persis mirip dengan awug. Hal itu menjadi alasan mengapa ia tertarik untuk membuatnya.

\section{SIMPULAN}

Budaya sunda memiliki ciri khasnya tersendiri, mulai dari seni, budaya, hingga kulinernya. Kuliner tradisional Sunda merupakan salah satu cara yang efektif untuk memperkenalkan budaya sunda kepada mahasiswa asing. Melalui kuliner, ciri khas dari budaya sunda itu akan lebih tertanam karena makanan adalah hal yang ditemui setiap hari oleh mahasiswa asing.

Dari paparan di atas disimpulkan bahwa mahasiswa asing memilih beberapa makanan karena berdasarkan faktorfaktor tertentu yang sangat mempengaruhi penilaian makanan di antaranya adalah selera makanan mereka dan standar makanan yang ada di negara masing-masing. Ada pula alasan pemilihan makanan berdasarkan selera makanan secara individual, tetapi hal itu tetap dipengaruhi oleh latar belakang selera dan kecocokan makanan yang biasa disajikan dari negara masing-masing.

Dari kegiatan sosialisasi kuliner ini ditunjukkan hasil bahwa mahasiswa asing sangat mengapresiasi kuliner tradisional Sunda ini. Berdasarkan antusiasme yang ditunjukkan selama kegiatan dan jawaban pada kuesioner yang dibagikan kepada mahasiswa asing, kegiatan sosialisasi kuliner Sunda merupakan hal yang sangat penting untuk diketahui mereka dan diharapkan dapat berjalan terus secara kontinyu dengan berbagai pengembangan.

\section{UCAPAN TERIMAKASIH}

Ucapan terima kasih disampaikan kepada Rektor Universitas Padjadjaran, Direktur Riset Pengabdian dan Inovasi, dan Dekan Fakultas Ilmu Budaya Universitas Padjadjaran yang telah memberi hibah pengabdian, serta mahasiswa Program KKNM Unpad Terintegrasi sehingga program kegiatan pengabdian ini dapat berlangsung dengan lancar dan sukses.

\section{DAFTAR PUSTAKA}

Dienaputra, R.D. 2011. Sunda: Sejarah, Budaya, dan Politik. Jatinangor: Sastra Unpad Press.

Ha, V.K.H. 2016. Peran Diplomasi Budaya dalam Mewujudkan Komunitas Sosial-Budaya

Asean: Kasus Vietnam. Jurnal Khazanah Pendidikan. Vol. X, No. 1 September 2016.

Harsojo. 1988. Pengantar Antropologi (Cetakan ketujuh). Bandung: Binacipta

Hennida, C. 2008. Diplomasi Publik dan Politik Luar Negeri. ( h t t p s : / / journal.unair.ac.id/filerPDF/03_Hennida_ DIPLOMASI\%20PUBLI

K.pdf, diakses 26 Maret 2019)

Koentjaraningrat. 2005. Pengantar Antropologi Jilid I. Jakarta: Rineka Cipta.

Rockower, P.S. 2011. Projecting Taiwan: Taiwan's Public Diplomacy Outreach 47, (Taiwan,

Taipei, Institute of International Relations, National Chengchi University, Maret 2011), hlm. 107-152.

Pujayanti, E. 2017. Gastrodiplomasi: Upaya Memperkuat Diplomasi Indonesia. Jurnal Politica. Vol. 8 No. 1 Mei 2017: hlm. 161-183.

Zakaria, M.M., Nani Sumarni, Dade Mahzuni, Rina Adyawardhina, Awaludin Nugraha, Sandya

Maulana, dan N. Kartika. 2011. Kajian Identifikasi Permasalahan Kebudayaan Sunda: Masa Lalu, Masa Kini, dan Masa yang Akan Datang. Laporan Penelitian, Jatinangor: Universitas Padjadjaran.

https://kumparan.com/@millennial/10-kampus-terbaikdi-indonesia-versi-qs-world-university-rankin gs-2019-1545028341237379369 diakses 26 Maret 2019. 